\title{
Serum concentrations of soluble (s)L- and (s)P-selectins in women with ovarian cancer
}

\author{
Dominika B. Majchrzak-Baczmańska ${ }^{1}$ Ewa Głowacka², Miłosz Wilczyński ${ }^{1}$, Andrzej Malinowski ${ }^{1}$ \\ ${ }^{1}$ Department of Surgical, Endoscopic and Oncologic Gynecology, Polish Mother's Memorial Hospital - Research Institute, Lodz, Poland \\ ${ }^{2}$ Centre of Medical Laboratory Diagnostics, Polish Mother's Memorial Hospital - Research Institute, Lodz, Poland
}

\begin{abstract}
Introduction: The aim of the study was to compare serum concentration of soluble L- and P-selectins in women with ovarian cancer (OC) and healthy controls, and to investigate SL- and SP-selectin levels with regard to clinical and pathological parameters. Correlation analysis was used to measure the following: SL- and SPselectin concentration and Ca125; SP-selectin and platelet concentrations; and sL-selectin and serum leukocyte levels in women with OC.

Material and methods: The study included 29 patients with OC and 23 healthy controls. Serum concentrations of SL- and SP-selectins were measured in all subjects. Routine diagnostic tests: CBC and USG (both groups) and Ca125 (study group) were performed.

Results: Significantly higher serum concentrations of SL- and SP-selectins were found in the study group as compared to controls. Lower levels of serum SL-selectin were observed in women with poorly-differentiated OC (G3) and advanced stages of the disease (FIGO III, IV), but the results were statistically insignificant. No statistically significant relationship was detected between sP-selectin serum concentration in women with OC and tumour differentiation, histological type, and stage of the disease. No significant correlation was found between SL- and SP-selectins and Ca125 levels. A weak correlation was found between serum concentration of sP-selectin in women with $\mathrm{OC}$ and platelet count. No statistically significant correlation was observed between sL-selectin concentration and serum leukocyte levels in women with OC.

Conclusions: The analysis of SL- and SP-selectin concentrations may be a useful tool in the diagnosis of OC. The levels of sL-selectin decrease with disease progression.
\end{abstract}

Key words: ovarian cancer, adhesion molecules, selectins.

\section{Introduction}

Ovarian cancer (OC), due to its hidden and/or atypical symptoms, and ineffective diagnostic and screening tools, is most commonly diagnosed in the advanced stages of the disease, when the five-year survival rate is $28 \%$ and $16 \%$ for stages III and IV, respectively. In contrast, the 5-year survival rate for stage I is approximately $80 \%$ [1]. Thus, it is vital to find new parameters and effective diagnostic methods to detect OC early because it might improve the prognosis and survival rates of the affected patients.

L- and P-selectins (CD62) belong to the family of calcium-dependent cell adhesion molecules that mediate the specific reaction between endothelial cells, leukocytes, and blood platelets [2-4]. L-selectin is present on the surface of all leukocyte types, and it partakes in the recruitment and rolling of leukocytes. P-selectin is found in the endothelium, as well as alpha granules and
Weibel-Palade bodies of platelets after activation and degranulation. It mediates neutrophil and monocyte adhesion in inflammation and coagulation. Selectins may take two different forms: cytoplasmic membranebound and soluble, released into the circulation and found in body fluids [2-4].

Studies on the role of $\mathrm{L}$ - and P-selectins in the biology of malignant neoplasms indicate that molecules may take part in the process of carcinogenesis mainly at the stage of distant metastases. The process of haematogenous metastases may depend on the interaction between tumour cells and thrombocytes. The ability of the circulating tumour cells to interact with platelets assures their survival in the circulation and may facilitate and promote the formation of metastatic foci [5]. Interactions of tumour cells with thrombocytes protect the tumour from the attacking phagocytes and enable tumour escape from immune surveillance. Additionally, as a result of degranulation, angiogenic and 
growth factors are released, and they might also stimulate the process of carcinogenesis. According to some authors, SP-selectin may be an indicator of platelet activation [5]. Also, studies point to the role of leukocytes in the formation of platelet or tumour embolisms, i.e. their role in the process of distant metastases. Leukocyte recruitment to metastatic sites depends of the activity of L-selectin, whose absence weakens the process of metastasis [6]. Elevated levels of soluble forms of P- and L-selectins have been demonstrated in sera of patients with various malignancies: colorectal and lung cancer, lymphoma, malignant melanoma, bladder cancer, multiple myeloma, breast cancer, and acute myeloid leukaemia [2-3, 6-17]. However, to the best of our knowledge, the literature offers no reports on serum SL- and sP-selectin concentrations in women with OC.

\section{Aim of the study}

The aim of the study was to compare serum concentrations of soluble SL- and SP-selectins in women with $\mathrm{OC}$ vs. healthy controls, and to investigate sL-selectin and SP-selectin levels with regard to clinical and pathological parameters. Also, correlation analysis was used to measure the following: i) SL- and SP-selectin concentration and Ca125; ii) sP-selectin and platelet concentrations; and iii) SL-selectin and serum leukocyte levels in women with OC.

\section{Patient characteristics and inclusion criteria}

A total of 52 patients from the Clinic of Surgical, Endoscopic and Oncologic Gynaecology, Polish Mother's Memorial Hospital in Łódź, constituted the study population, including 29 women with OC and 23 controls with no malignancies.

The local Ethics Committee approved of the study (nr: 71/2012). Serum SL- and sP-selectin levels were measured in all subjects, followed by routine diagnostic tests: CBC and USG (both groups), and Ca125 (study group). All patients gave their informed consent to participate in the study. All subjects from the study group were treated in accordance with the oncological protocol. The exclusion criteria were: history of chemotherapy or radiotherapy due to malignant neoplasms, history of any malignancy, recurrent OC (the study included only patients with primary $\mathrm{OC}$ with no previous treatment), and hormonal therapy (contraceptives, HRT, etc.).

\section{Immunoenzymatic analysis of serum sL- and sP-selectin concentration}

In the morning, $5 \mathrm{ml}$ of fasting blood samples were drawn into serum gel tubes and transported to the lab- oratory within one hour of collection. Next, the samples were centrifuged at $1500 \times \mathrm{g}$ for $10 \mathrm{~min}$., and serum was gently separated and stored at $-80^{\circ} \mathrm{C}$ until used. The $\mathrm{SL}$ - and SP-selectin concentrations were tested with immunoenzymatic ELISA using commercially available kits (R\&D): Human SL-Selectin Immunoassay (sensitivity: $0.3 \mathrm{ng} / \mathrm{m}$ ), Human sP-Selectin Immunoassay (sensitivity: $0.5 \mathrm{ng} / \mathrm{ml}$ ), according to the manufacturer's protocol. Absorbance was measured at $450 \mathrm{~nm}$ in an ELx 808 reader. The results are expressed as $\mathrm{ng} / \mathrm{ml}$.

\section{Statistical analyses}

Statistical analyses were carried out using the following tests:

- the Shapiro-Wilk W to test the distribution for normality,

- U Mann-Whitney to test quantitative parameters between two groups with non-normal distribution or groups with statistically significantly different sample size ( $\chi^{2}$ test was used to check equality of group proportions),

- ANOVA rang Kruskal-Wallis to test quantitative parameters between more than two groups with nonnormal distribution or groups with statistically significantly different sample size ( $\chi^{2}$ test was used to check equality of group proportions),

- Pearson's correlation coefficient for normally distributed variables and Spearman's rank correlation for non-normally distributed quantitative variables,

- Independent Pearson's $\chi^{2}$ to compare qualitative variables between two groups.

Statistical analysis was performed using STATISTICA 6.0 , and a $p$-value $<0.05$ was considered as statistically significant.

\section{Results}

Mean patient age in the group of women with OC was approximately 50 years. Mean BMI was $26.80 \mathrm{~kg} / \mathrm{m}^{2}$. Twenty (68.97\%) patients from the study group had normal menstruation and $9(31.03 \%)$ were postmenopausal. There were 6 (20.69\%) primiparas, 19 (65.52\%) multiparas, and 4 (13.79\%) nulliparas in the study group. BRCA 1 gene mutation was found in one patient (Table 1).

No statistically significant differences were found with regard to basic patient characteristics (age, BMI, parity, menopausal status, and concomitant diseases) between the study group and controls (Table 1).

Out of 29 patients with OC, 16 (55.17\%) were diagnosed with serous adenocarcinoma, three (10.34\%) with undifferentiated adenocarcinoma, two (6.90\%) with clear-cell adenocarcinoma, two (6.90\%) with anaplastic carcinoma, two (6.90\%) with mucinous adenocarcino- 
Table 1. Statistical analysis of patient characteristics in the study and control groups

\begin{tabular}{|c|c|c|c|c|}
\hline Parameter & $\begin{array}{l}\text { Study group } \\
\quad(n=29)\end{array}$ & $\begin{array}{l}\text { Control group } \\
\quad(n=23)\end{array}$ & Test & $p$ \\
\hline Age & & & Cochran and $\mathrm{Cox}=-1.22547$ & $>0.05$ \\
\hline $\begin{array}{l}\text { Mean } \\
\text { Min. - max. } \\
\text { Median } \\
\text { SD }\end{array}$ & $\begin{array}{c}50 \text { years } \\
26-85 \text { years } \\
49 \text { years } \\
\pm 10.80\end{array}$ & $\begin{array}{c}53.61 \text { years } \\
45-70 \text { years } \\
52 \text { years } \\
\pm 6.47 \text { years }\end{array}$ & & \\
\hline $\mathrm{BMI}$ & & & $\mathrm{T}=-0.861637$ & $>0.05$ \\
\hline $\begin{array}{l}\text { Mean } \\
\text { Min. - max. } \\
\text { Median } \\
\text { SD }\end{array}$ & $\begin{array}{c}26.80 \mathrm{~kg} / \mathrm{m}^{2} \\
17.94-36.72 \mathrm{~kg} / \mathrm{m}^{2} \\
26.88 \mathrm{~kg} / \mathrm{m}^{2} \\
\pm 5.62 \mathrm{~kg} / \mathrm{m}^{2}\end{array}$ & $\begin{array}{c}28.12 \mathrm{~kg} / \mathrm{m}^{2} \\
20.55-40.04 \mathrm{~kg} / \mathrm{m}^{2} \\
26.04 \mathrm{~kg} / \mathrm{m}^{2} \\
\pm 5.33 \mathrm{~kg} / \mathrm{m}^{2}\end{array}$ & & \\
\hline Menopausal status & & & $\chi^{2}$ Pearson $=0.856577$ & $>0.05$ \\
\hline $\begin{array}{l}\text { Post-menopausal } \\
\text { Menstruating }\end{array}$ & $\begin{array}{c}9(31.03 \%) \\
20(68.97 \%)\end{array}$ & $\begin{array}{l}10(43.48 \%) \\
13(56.52 \%)\end{array}$ & & \\
\hline Parity & & & $\chi^{2}$ Pearson $=2.213351$ & $>0.05$ \\
\hline $\begin{array}{l}\text { Nulliparas } \\
\text { Primiparas } \\
\text { Multiparas }\end{array}$ & $\begin{array}{c}4(13.79 \%) \\
6(20.69 \%) \\
19(65.52 \%)\end{array}$ & $\begin{array}{c}3(13.04 \%) \\
9(39.13 \%) \\
11(47.83 \%)\end{array}$ & & \\
\hline Comorbidities: & & & $\chi^{2}$ Pearson $=0.2963878$ & $>0.05$ \\
\hline $\begin{array}{l}\text { None } \\
\text { Cardiovascular diseases } \\
\text { Cardiovascular diseases \& DM } \\
\text { DM }\end{array}$ & $\begin{array}{c}16(55.17 \%) \\
9(31.03 \%) \\
4(13.79 \%) \\
0(0 \%)\end{array}$ & $\begin{array}{c}11(47.83 \%) \\
8(34.78 \%) \\
4(17.39 \%) \\
0(0 \%)\end{array}$ & & \\
\hline
\end{tabular}

ma, and four (13.79\%) with endometrioid adenocarcinoma (Table 2). The tumour was well-differentiated (G1) in three (10.34\%), moderately-differentiated (G2) in eight (27.59\%), and poorly-differentiated (G3) in 18 (62.02\%) women. As a result, three (10.34\%) patients were diagnosed with stage I, 12 (41.38\%) with stage III, and 14 (48.28\%) with stage IV FIGO OC. No grade II FIGO cancer cases were found in the studied population (Table 2).

Serum SL- and SP-selectin concentrations were statistically significantly higher in women with $\mathrm{OC}$ as compared to controls (Table 3). Lower serum sL-selectin levels were detected in women with poorly-differentiated (G3) OC and advanced stages of the disease (FIGO III and IV), but the results were not statistically significant. No statistical significance was found between serum sP-selectin levels in the study group and histological tumour type and differentiation, disease stage, and SLand SP-selectins/Ca125 correlation (Tables 4-7). A weak correlation between serum sP-selectin level and platelet count was observed in OC patients (Table 7). The results almost reached statistical significance. No statistically significant correlation between serum sL-selectin and leukocyte levels was detected in the study group (Table 7).

\section{Discussion}

To the best of our knowledge, our study has been the first to evaluate serum SP- and SL-selectin levels in
Table 2. Clinical and pathological characteristics of the study group (supplemental)

\begin{tabular}{lc}
\hline Characteristics & $\begin{array}{c}\text { Study group IV } \\
(n=29)\end{array}$ \\
\hline Histological type & \\
\hline Adenocarcinoma serosum & $16(55.17 \%)$ \\
Adenocarcinoma male differentiatum & $3(10.34 \%)$ \\
Adenocarcinoma clarocellulare & $2(6.90 \%)$ \\
Carcinoma anaplasticum & $2(6.90 \%)$ \\
Adenocarcinoma mucinosum & $2(6.90 \%)$ \\
Adenocarcinoma endometrioides & $4(13.79 \%)$ \\
\hline Grading & \\
\hline G1 & $3(10.34 \%)$ \\
G2 & $8(27.59 \%)$ \\
G3 & $18(62.02 \%)$ \\
\hline FIGO stage & \\
\hline I & $3(10.34 \%)$ \\
II & $0(0.00 \%)$ \\
III & $12(41.38 \%)$ \\
IV & $14(48.28 \%)$ \\
\hline
\end{tabular}

OC and to find a statistically significant relationship between OC patients and healthy controls. The literature offers a limited number of publications about the role of L- and P-selectins in the pathogenesis of OC. Also, the available reports analysed only the transmembrane forms of these molecules, the effect of pharmacologic agents on their expression, and the presence of their ligands. Thrombocytosis and thrombosis are common complications of malignant neoplasms, including OC 
Table 3. Statistical analysis of serum SL/sP-selectin concentrations in patients with $\mathrm{OC}$ and controls

\begin{tabular}{lcc}
\hline sL-selectin $[\mathrm{ng} / \mathrm{ml}]$ & Study group & Control group \\
\hline No. of patients & 29 & 23 \\
\hline Min. & 557.00 & 284 \\
\hline Max. & 1560.00 & 1000.00 \\
\hline Median & 881.00 & 640 \\
\hline Arithmetical mean & 983.48 & 589.65 \\
\hline Standard deviation & 314.24 & 206.81 \\
\hline Asymmetry coefficient & 0.70 & 0.34 \\
\hline Statistical analysis & $U$ Mann-Whitney test $=-4.42210 ;$ \\
\hline sP-selectin [ng/ml] & \multicolumn{2}{c}{$p<0.05$} \\
\hline No. of patients & 29 & Control group \\
\hline Min. & 31.60 & 23 \\
\hline Max. & 311.00 & 10.40 \\
\hline Median & 107.40 & 60.20 \\
\hline Arithmetical mean & 128.78 & 63.44 \\
\hline Standard deviation & 71.95 & 34.19 \\
\hline Asymmetry coefficient & 0.89 & 0.39 \\
\hline Statistical analysis & U Mann-Whitney test $=-3.60209 ;$ \\
\hline & \multicolumn{2}{c}{$p<0.05$} \\
\hline
\end{tabular}

Table 5. Statistical analysis of serum $\mathrm{sL} / \mathrm{sP}$-selectin concentrations in patients with $\mathrm{OC}$ with regard to tumour grade

\begin{tabular}{lccc}
\hline sL-selectin [ng/ml] & \multicolumn{3}{c}{ Tumour grade } \\
\cline { 2 - 4 } & G1 & G2 & G3 \\
\hline No. of patients & 3 & 8 & 18 \\
\hline Min. & 788.00 & 730.00 & 557.00 \\
\hline Max. & 1530.00 & 1526.00 & 1560.00 \\
\hline Median & 902.00 & 984.50 & 855.00 \\
\hline Arithmetical mean & 1073.33 & 1055.50 & 936.50 \\
\hline Standard deviation & 399.57 & 331.68 & 303.91 \\
\hline Asymmetry coefficient & 1.57 & 0.55 & 0.86 \\
\hline Statistical analysis & Kruskal-Wallis ANOVA $=0.849461 ;$ \\
\hline sP-selectin [ng/ml] & \multicolumn{4}{c}{ Tumour grade } \\
\cline { 2 - 4 } & G1 & G2 \\
\hline No. of patients & 3 & 8 & G3 \\
\hline Min. & 72.80 & 59.40 \\
\hline Max. & 125.60 & 209.80 & 31.60 \\
\hline Median & 124.20 & 134.40 \\
\hline Arithmetical mean & 107.53 & 137.53 & 94.10 \\
\hline Standard deviation & 30.09 & 54.47 & 96.07 \\
\hline Asymmetry coefficient & -1.73 & -0.04 & 1.22 \\
\hline Statistical analysis & Kruskal-Wallis ANOVA $=0.868391 ;$ \\
\hline \multicolumn{4}{c}{$p>0.05$} \\
\hline
\end{tabular}

Table 4. Statistical analysis of serum sL/sP-selectin concentrations in patients with $\mathrm{OC}$ with regard to histological tumour type

\begin{tabular}{lcc}
\hline sL-selectin [ng/ml] & \multicolumn{2}{c}{ Histological tumour type } \\
\cline { 2 - 3 } & $\begin{array}{c}\text { Adenocarcinoma } \\
\text { serosum ovarii }\end{array}$ & Others \\
\hline No. of patients & 16 & 13 \\
\hline Min. & 557.00 & 617.00 \\
\hline Max. & 1560.00 & 1530.00 \\
\hline Median & 826.50 & 949.00 \\
\hline Arithmetical mean & 931.63 & 1047.95 \\
\hline Standard deviation & 318.24 & 309.55 \\
\hline Asymmetry coefficient & 0.96 & 0.60 \\
\hline Statistical analysis & $U$ Mann-Whitney test $=-1.18432 ;$ \\
\hline sP-selectin [ng/ml] & $p>0.05$ \\
\cline { 2 - 3 } & Histological tumour type \\
\hline No. of patients & Adenocarcinoma & Others \\
\hline Min. & 16 & 13 \\
\hline Max. & 49.20 & 31.60 \\
\hline Median & 265.00 & 363.60 \\
\hline Arithmetical mean & 98.30 & 124.20 \\
\hline Standard deviation & 125.58 & 140.42 \\
\hline Asymmetry coefficient & 65.57 & 98.11 \\
\hline Statistical analysis & 0.67 & 1.38 \\
\hline & U Mann-Whitney test $=-0.087706 ;$ \\
\hline
\end{tabular}

Table 6. Statistical analysis of serum SL/sP-selectin concentrations in patients with $\mathrm{OC}$ with regard to FIGO stage

\begin{tabular}{lcccc}
\hline sL-selectin [ng/ml] & \multicolumn{5}{c}{ Figo stage } \\
\cline { 2 - 5 } & I & II & III & IV \\
\hline No. of patients & 3 & 0 & 12 & 14 \\
\hline Min. & 696.00 & - & 609.00 & 557.00 \\
\hline Max. & 1530.00 & - & 1526.00 & 1560.00 \\
\hline Median & 902.00 & - & 839.50 & 966.00 \\
\hline Arithmetical mean & 1042.67 & - & 972.08 & 980.57 \\
\hline Standard deviation & 434.43 & - & 327.01 & 303.70 \\
\hline Asymmetry coefficient & 1.30 & - & 0.90 & 0.62 \\
\hline Statistical analysis & Kruskal-Wallis ANOVA $=0.118942 ;$ \\
\hline sP-selectin [ng/ml] & \multicolumn{5}{c}{ F > 0.05 } \\
\cline { 2 - 5 } & I IGO stage \\
\hline No. of patients & 3 & II & III & IV \\
\hline Min. & 72.80 & - & 12 & 14 \\
\hline Max. & 192.40 & - & 363.20 & 31.60 \\
\hline Median & 124.20 & - & 135.90 & 96.20 \\
\hline Arithmetic mean & 129.80 & - & 153.20 & 114.77 \\
\hline Standard deviation & 60.00 & - & 93.25 & 72.94 \\
\hline Asymmetry coefficient & 0.42 & - & 1.08 & 1.58 \\
\hline Statistical analysis & Kruskal-Wallis ANOVA $=1.196223 ;$ \\
\hline \multicolumn{5}{c}{$p>0.05$} \\
\hline
\end{tabular}


$[5,18]$. Studies on the role of platelets in the origin of OC metastases revealed that the ability of cancerous cells to activate platelets was related to increased expression of P-selectin as a result of thrombocyte degranulation $[5,18]$. P-selectin overexpression was found to be higher in metastatic as compared to non-metastatic OC and normal ovarian surface epithelium [5]. According to the accumulated body of evidence, $\mathrm{P}$ - and L-selectins may bind to sulphatides present not only on the surface of granulocytes but also of the tumour cells $[19,20]$. A positive correlation between high concentration of sulphatides and poor prognosis in ovarian and colorectal cancers was found [21]. Also, numerous malignancies, including OC, were proven to express CD24, a ligand for P-selectin. P-selectin binds to CD24 present on the surface of the tumour cells, causing tumour cell adhesion and, consequently, metastatic spread [22, 23]. CD24 shows no expression on normal ovarian surface epithelium, whereas cytoplasmic CD24 activity significantly correlates with poor prognosis in the affected women in cases of invasive forms of ovarian cancer [24, 25].

After platelet activation and degranulation, the expression of P-selectin on the surface thrombocytes is temporary, while its soluble form is released and may be detected in the serum. Elevated levels of sP-selectin in cancer patients are believed to be the sign of thrombocyte activation, resulting from their interaction with cancer cells, and might indirectly signal the induction of metastatic spread. Various authors suggest that evaluation of soluble P-selectin concentration is a better indicator of thrombocyte activation than the expression of its transmembrane form [9]. Therefore, we analysed the correlation between SP-selectin concentration and thrombocyte levels in patients with OC. A weak positive correlation between sP-selectin level and platelet count was detected. Our results almost reached statistical significance. Increased sP-selectin concentration was noted also in other malignant neoplasms [2, 3, 7-12]. Moreover, a positive correlation between sP-selectin concentration and thrombocyte levels was also confirmed [7, 9]. Also, sP-selectin concentration was found to be an independent prognostic factor of disease recurrence and death in colorectal cancer [7]. Evaluation of the sP-selectin level is believed to be a sensitive marker of disease progression in patients with malignant melanoma [10]. Also, a correlation between serum sP-selectin and disease advancement as well as distant metastases was observed in patients with colorectal and lung cancers, lymphoma, and melanoma [7-10], which might confirm the hypothesis about the effect of the interaction between cancer-cells and thrombocytes in metastatic spread [9].

In our study, we found no relationship between serum SP-selectin concentration in women with $\mathrm{OC}$ and either clinical and pathological parameters or Ca125 levels. Other authors, despite having detected elevated
Table 7. Statistical analysis of the correlation (Spearman's rank - R): between serum SL- and SP-selectin concentration and chosen parameters in patients with $O C$

\begin{tabular}{lcc}
\hline \multirow{2}{*}{ Parameter } & \multicolumn{2}{c}{ Ca125 } \\
\cline { 2 - 3 } & $R$ & $p$ \\
\hline SL-selectin & -0.127125 & $>0.05$ \\
\hline sP-selectin & 0.055665 & $>0.05$ \\
\hline Parameter & \multicolumn{2}{c}{ WBC } \\
\cline { 2 - 3 } & \multicolumn{2}{c}{$p$} \\
\hline SL-selectin & -0.033013 & PLT \\
\hline Parameter & \multicolumn{2}{c}{$p$} \\
\cline { 2 - 3 } & $R$ & \multicolumn{2}{c}{$p$} \\
\hline sP-selectin & 0.366010 & $>0.05(p=0.050857)$ \\
\hline
\end{tabular}

serum sP-selectin levels in patients with various malignancies (colorectal and bladder cancers), also failed to observe the existence of a correlation between SPselectin levels and clinical and pathological parameters [2-3]. In our study, the lack of statistically significant differences with regard to the clinical and pathological parameters is probably connected with the small sample size. Further studies with larger samples might clarify the matter.

L-selectin not only takes part in the metastatic spread, participating in leukocyte recruitment to metastatic foci, but also, through activation of the inflammatory process, creates a favourable microenvironment for metastatic cells [26]. Various studies confirm that L-selectin promotes the survival of the tumour cells as soon as 12-24 hours after their migration into the circulation. Leukocytes that express L-selectin may assist tumour cells in their penetration of the endothelium and facilitate the metastatic spread [27]. Additionally, heparin was shown to block L- and P-selectin activity, impeding the process of distant metastases in malignant tumours, including OC $[28,29]$.

The release of soluble L-selectin from the surface of the leukocytes is believed to be the regulatory mechanism of expression and function of its transmembrane form. As a result of the sL-selectin release, its expression on the surface of the leukocytes decreases. Consequently, the ability of neutrophil migration to the site of inflammatory process, and binding to the endothelium of microvessels of the lymph nodes, is significantly lowered. A release of soluble L-selectin from the surface of leukocytes regulates their activity, and modulates the inflammatory response [4]. Serum sL-selectin levels have rarely been investigated in patients with malignant tumours. The exact role of SL-selectin in the process of carcinogenesis remains to be fully elucidated.

The results of other authors who also detected increased serum sL-selectin concentrations in patients with various malignant neoplasms are consistent with our findings [11, 13-17]. Czygier et al. observed elevated 
serum sL-selectin levels in women with early-stage breast cancer (grade I and II) as compared to healthy controls [13]. However, the same authors found lowered serum concentrations of sL-selectin in subjects with advanced breast cancer (grade III and IV), and reported a further decrease after chemotherapy. They hypothesised that it resulted from a lower number of granulocytes and their deteriorated function caused by the advanced-stage tumour and chemotherapy [30]. Elevated serum sL-selectin levels were also observed in patients with acute myeloid and lymphoblastic leukaemia before treatment and during disease recurrence, as well as an increase in SL-selectin concentrations with tumour progression and a decrease in patients with remission $[14,17]$. Interestingly, Czygier et al. found lower SL-selectin concentrations in patients with endometrial cancer and cervical cancer as compared to controls. These authors concluded it was the consequence of disrupted rolling of neutrophils [31]. However, it is a well-known fact that lowered expression of the transmembrane form and decreased ability of leukocytes to migrate are the results of sL-selectin release, so that explanation is not satisfactory.

In our study, we detected decreased concentrations of serum SL-selectin in women with poorly-differentiated OC (G3), and with advanced stages of the disease (FIGO III, IV), but the results were not statistically significant. Our findings might suggest that intensified release of sL-selectin from leukocyte surface occurs at the beginning of OC carcinogenesis, leading to lowered expression of its transmembrane form and hindered ability of neutrophils to migrate to the tumour site. Possibly, that is how the tumour escapes from immune surveillance and avoids destruction. Regardless, the tumour has the ability of modulating leukocyte properties, and WBC play a role in the process of metastases. Thus, it seems plausible that, together with disease progression, the degree of sL-selectin release is lowered to increase the expression of its transmembrane form and restore migration ability in leukocytes. In that way, leukocytes might promote tumour-cell survival, assist them in the process of penetrating the endothelial barrier, and facilitate metastatic spread. L-selectin expression on the surface of WBC, through activation of the inflammatory process, might create a favourable microenvironment for metastatic cells. That hypothesis might be supported by the findings of Czygier et al., who detected increased levels of serum sL-selectin in women with early-stage breast cancer and decreased levels of serum sL-selectin in subjects with advanced stages of the disease (grade III and IV) [13, 30]. However, further studies with a large sample size are necessary. In our study, lack of statistical significance was most probably the result of a small sample size.

In our study, no statistically significant correlation between serum sL-selectin in women with $O C$ and leukocyte levels was found. It might indicate that the amount of soluble sL-selectin depends on the expression intensity of its transmembrane form, rather that WBC count, especially that the process of releasing SLselectin constitutes a regulatory mechanism of its activity on leukocytes [4].

\section{Conclusions}

The analysis of soluble L- and P-selectin concentrations may be a useful tool in OC diagnosis. Evaluation of soluble P-selectin concentration could be a good indicator of thrombocyte activation in cancer progression. The levels of sL-selectin decrease with disease progression.

\section{Disclosure}

Authors report no conflict of interest.

\section{References}

1. Yang YI, Kim JH, Lee KT, et al. Costunolide induces apoptosis in platinumresistant human ovarian cancer cells by generating reactive oxygen species. Gynecol Oncol 2011; 123: 588-596.

2. Dymicka-Piekarska V, Kemona H. Does colorectal cancer clinical advancement affect adhesion molecules (sP-selectin, sE-selectin and ICAM-1) concentration? Thromb Res 2009; 124: 80-83.

3. Coskun U, Sancak B, Sen I, et al. Serum P-selectin, soluble vascular cell adhesion molecule-I (s-VCAM-I) and soluble intercellular adhesion molecule-I (s-ICAM-I) levels in bladder carcinoma patients with different stages. Int Immunopharmacol 2006; 6: 672-677.

4. Smalley DM, Ley K. L-selectin: mechanisms and physiological significance of ectodomain cleavage. J Cell Mol Med 2005; 9: 255-266.

5. Egan K, Crowley D, Smyth P, et al. Platelet adhesion and degranulation induce pro-survival and pro-angiogenic signalling in ovarian cancer cells. PLoS One 2011; 6: e26125.

6. Bendas G, Borsig L. Cancer cell adhesion and metastasis: selectins, integrins, and the inhibitory potential of heparins. Int J Cell Biol 2012; 2012: 676731.

7. Ferroni P, Roselli M, Martini F, et al. Prognostic value of soluble P-selectin levels in colorectal cancer. Int J Cancer 2004; 111: 404-408.

8. Roselli M, Mineo TC, Martini F, et al. Soluble selectin levels in patients with lung cancer. Int J Biol Markers 2002; 17: 56-62.

9. Dymicka-Piekarska V, Matowicka-Karna J, Gryko M, et al. Relationship between soluble P-selectin and inflammatory factors (interleukin- 6 and C-reactive protein) in colorectal cancer. Thromb Res 2007; 120: 585-590.

10. Schadendorf D, DiehI S, Zuberbier T, et al. Quantitative detection of soluble adhesion molecules in sera of melanoma patients correlates with clinical stage. Dermatology 1996; 192: 89-93.

11. Haznedaroglu IC, Benekli M, Ozcebe O, et al. Serum L-selectin and P-selectin levels in lymphomas. Haematologia (Budap) 2000; 30: 27-30.

12. Aki SZ, Sucak GT, Paşaoğlu H, et al. Thrombopoietic cytokine and P-selectin levels in patients with multiple myeloma undergoing autologous stem cell transplantation: decrease in posttransplantation P-selectin levels might predict the degree of maximum response. Clin Lymphoma Myeloma 2009; 9: 229-233.

13. Czygier M, Ławicki S, Szmitkowski M. The plasma level of sL-selectin, myeloperoxidase (MPO) and granulocyte-colony stimulating factor (G-CSF) in breast cancer patients after surgery Przegl Lek 2009; 66: 433-436.

14. Chang JH, Qi ZH, Xu M. Clinical significance of the detection of the SLselectin level in patients with acute leukemia. Hunan Yi Ke Da Xue Xue Bao 2002; 27: 151-153.

15. Izycka A, Jabłońska E, Izycki T, Chyczewska E. Expression of L-selectin on the surface of neutrophils stimulated by TNF-alpha and level of 
SL-selectin in serum of patients with lung cancer. Pol Merkur Lek 2005; 18: 62-65.

16. Kiersnowska-Rogowska B, Izycka A, Jabłońska E, et al. Estimation of L-selectin expression on neutrophils and level of soluble L-selectin form in serum of patient with chronic myelogenic leukemia. Przegl Lek 2006; 63: 756-758.

17. Aref S, Salama O, Al-Tonbary Y, et al. L and E selectins in acute myeloid leukemia: expression, clinical relevance and relation to patient outcome. Hematology 2002; 7: 83-87.

18. Bazou D, Santos-Martinez MJ, Medina C, Radomski MW. Elucidation of flow-mediated tumour cell-induced platelet aggregation using an ultrasound standing wave trap. Br J Pharmacol 2011; 162: 1577-1578.

19. Garcia J, Callewaert N, Borsig L. P-selectin mediates metastatic progression through binding to sulfatides on tumor cells. Glycobiology 2007; 17: 185-196.

20. Suzuki Y, Toda Y, Tamatani T, et al. Sulfated glycolipids are ligands for a lymphocyte homing receptor, L-selectin (LECAM-1), Binding epitope in sulfated sugar chain. Biochem Biophys Res Commun 1993; 190: 426-434.

21. Sugiyama T, Miyazawa M, Mikami M, et al. Enhanced expression of sulfatide, a sulfated glycolipid, in well-differentiated endometrial adenocarcinoma. Int J Gynecol Cancer 2012; 22: 1192-1197.

22. Aigner S, Sthoeger ZM, Fogel M, et al. CD24, a mucin-type glycoprotein, is a ligand for P-selectin on human tumor cells. Blood 1997; 89: 3385 3395.

23. Lim SC, Oh SH. The role of CD24 in various human epithelial neoplasias. Pathol Res Pract 2005; 201: 479-486.

24. Kristiansen G, Denkert C, Schlüns K, et al. CD24 is expressed in ovarian cancer and is a new independent prognostic marker of patient survival. Am J Pathol 2002; 161: 1215-1221.

25. Surowiak P, Materna V, Kaplenko I, et al. Unfavorable prognostic value of CD24 expression in sections from primary and relapsed ovarian cancer tissue. Int J Gynecol Cancer 2006; 16: 515-521.

26. Laubli H, Spanaus K S, Borsig L. Selectin-mediated activation of endothelial cells induces expression of CCL5 and promotes metastasis through recruitment of monocytes. Blood 2009; 114: 4583-4591.

27. Läubli H, Stevenson JL, Varki A, et al. L-selectin facilitation of metastasis involves temporal induction of Fut7-dependent ligands at sites of tumor cell arrest. Cancer Res 2006; 66: 1536-1542.

28. Bendas G, Borsig L. Cancer cell adhesion and metastasis: selectins, integrins, and the inhibitory potential of heparins. Int J Cell Biol 2012; 2012: 676731 .

29. Chen Z, Jing Y, Song B, et al. Chemically modified heparin inhibits in vitro L-selectin-mediated human ovarian carcinoma cell adhesion. Int J Gynecol Cancer 2009; 19: 540-546.

30. Czygier M, Ławicki S, Uścinowicz A, et al. The plasma level of sL-selectin, myeloperoxidase and granulocyte-colony stimulating factor (G-CSF) in breast cancer patients in the course of chemotherapy Przegl Lek 2008; 65: 115-118.

31. Czygier M, Ławicki S, Gacuta-Szumarska E, Bedkowska E, et al. Stężenie sL-selektyny i mieloperoksydazy (MPO) oraz czynnika wzrostu koloni granulocytarnych (G-CSF) w osoczu pacjentek z nowotworami macicy. Przegl Lek 2010; 67: 184-186. 